\title{
Anti-Inflammatory, Immunomodulatory, and Antioxidant Activities of Allicin, Norfloxacin, or Their Combination against Pasteurella multocida Infection in Male New Zealand Rabbits
}

\author{
Rasha T. M. Alam, ${ }^{1}$ Elshaima M. Fawzi, ${ }^{2}$ Maha I. Alkhalf, ${ }^{3}$ Wafa S. Alansari, ${ }^{3}$ Lotfi Aleya, ${ }^{4}$ \\ and Mohamed M. Abdel-Daim ${ }^{5}{ }^{5}$ \\ ${ }^{1}$ Department of Clinical Pathology, Faculty of Veterinary Medicine, Zagazig University, Zagazig, 44511 Sharkia, Egypt \\ ${ }^{2}$ Department of Internal Medicine (Infectious Diseases), Faculty of Veterinary Medicine, Zagazig University, Zagazig, \\ 44511 Sharkia, Egypt \\ ${ }^{3}$ Biochemistry Department, Faculty of Science-Al Faisaliah, King Abdulaziz University, Jeddah, Saudi Arabia \\ ${ }^{4}$ Bourgogne Franche-Comté University, Chrono-Environnement Laboratory, UMR CNRS 6249, 25030 Besançon Cedex, France \\ ${ }^{5}$ Department of Pharmacology, Faculty of Veterinary Medicine, Suez Canal University, Ismailia 41522, Egypt
}

Correspondence should be addressed to Mohamed M. Abdel-Daim; abdeldaim.m@vet.suez.edu.eg

Received 15 February 2018; Accepted 8 April 2018; Published 27 June 2018

Academic Editor: Mansur A. Sandhu

Copyright $\odot 2018$ Rasha T. M. Alam et al. This is an open access article distributed under the Creative Commons Attribution License, which permits unrestricted use, distribution, and reproduction in any medium, provided the original work is properly cited.

\begin{abstract}
The present study investigated the efficacy of allicin as an antibacterial, anti-inflammatory, antioxidant, and immunostimulant agent in reducing the severity of Pasteurella multocida ( $P$. multocida) type B infection in rabbits. Fifty New Zealand rabbits, 5 weeks old, were divided equally into five groups. Except for group 1, all groups were intranasally infected with $P$. multocida type B $\left(2 \times 10^{5}\right.$ colony forming units/ml/rabbit). Then, group 3 rabbits were orally treated with allicin $(50 \mathrm{mg} / \mathrm{kg} \mathrm{BW})$ for 5 days, group 4 rabbits received a single oral dose of norfloxacin $30 \%(100 \mathrm{mg} / \mathrm{kg}$ BW), while group 5 rabbits were treated with a combination of norfloxacin and allicin. Hematological, serum biochemical, inflammatory cytokine, immunological, and histopathological analyses were performed. Results revealed that rabbits, infected with $P$. multocida type B, exhibited macrocytic hypochromic anemia and leukocytosis with a significant elevation in the phagocytic percentage and index. Moreover, significant reductions in serum total protein, albumin, globulin, and immunoglobulin (IgG and IgM) levels were observed in infected rabbits. Infected rabbits showed significant increases in serum inflammatory cytokine (TNF- $\alpha$ and IL-6), alanine aminotransferase, alkaline phosphatase, lactate dehydrogenase, and serum bilirubin (total, direct, and indirect) levels. Further, $P$. multocida infection induced oxidative stress as demonstrated by the significant reduction in serum levels of reduced glutathione and superoxide dismutase enzyme and marked elevation in serum malondialdehyde. Treatment with allicin, norfloxacin, or their combination significantly ameliorated the alterations in all studied parameters. In conclusion, allicin could ameliorate the inflammation and oxidative stress, induced by $P$. multocida type B infection in rabbits.
\end{abstract}

\section{Introduction}

Pasteurella multocida (P. multocida) is a microbe, which occurs naturally in the respiratory tract of some animal species; however, it can be a virulent pathogen that infects other animal hosts [1]. Pasteurellosis is a disease that affects rabbits, characterized by rhinitis, pneumonia, orchitis, otitis media, septicemia, and abscess formation [2]; however, infection with $P$. multocida may be asymptomatic [3].
Norfloxacin is a second-generation fluoroquinolone with a broad spectrum of activity, potent bactericidal action, and high tissue penetration $[4,5]$. Despite its efficacy, it has been shown that antibiotic traces which are present in animal products can affect human health directly due to side effects and impact on intestinal flora and precipitation or indirectly through increasing bacterial resistance to antibiotics (maximum residue limit for norfloxacin is $0.02-0.1$ in pig and poultry) [6]. The emergence of antibiotic resistance [7] and 
the rabbits' hypersensitivity to several antimicrobial agents precludes the extensive applications of antibiotics in this species [8].

Garlic (Allium sativum) is considered the oldest medicinal herb and had been used for the treatment of several diseases. It is effective against several gram-positive, gram-negative, and acid-fast bacteria [9]. Moreover, it has antioxidant, immunomodulatory, and anti-inflammatory effects [10-12]. Allicin is a major biologically active component of garlic clove extracts with a potent antioxidant activity [11]. Moreover, it has been shown to exert organoprotective effects against several xenobiotics, such as deltamethrin and doxorubicin $[13,14]$.

This study was performed to evaluate the ameliorative (antioxidant, anti-inflammatory, and immunomodulatory) effects of allicin alone or combined with norfloxacin in the treatment of $P$. multocida infection in rabbits.

\section{Material and Methods}

2.1. Experimental Animals. Male New Zealand white rabbits (850-1000 g, 5 weeks of age) were obtained from the Faculty of Veterinary Medicine, Zagazig University. Rabbits were housed in a pathogen-free facility, maintained at $24 \pm 2^{\circ} \mathrm{C}$ with a $50-60 \%$ relative humidity and a $12 \mathrm{~h}$ light: dark cycle. Rabbits had ad libitum access to tap water and basal ration. All rabbits were acclimatized for one week before beginning the experiment. Rabbit handling and treatment procedures were performed according to the Guidelines for the Care and Use of Laboratory Animals of the National Institutes of Health (NIH) and approved by a research ethics committee at the Faculty of Veterinary Medicine, Zagazig University. All efforts were exerted to reduce animal suffering.

2.2. Bacterial Strain. Pasteurella multocida type $B$ was obtained from the National Research Centre, Dokki (Giza, Egypt) and used for experimental infection with a final concentration of $2 \times 10^{5}$ colony-forming units (CFU) prior to inoculation.

2.3. Drugs. Norfloxacin was purchased from ATCO Pharma (Atonor 30, $300 \mathrm{mg} / \mathrm{ml}$, oral suspension). Allicin was obtained from Anhui Ruisen Biological Technology Co., China. All used kits were marketed by Spinreact, Spain.

2.4. Experimental Design. After acclimatization, fifty rabbits (6 weeks of age) were randomly allocated into five equal groups (10 rabbits for each group). Group 1 rabbits were given intranasal (IN) phosphate-buffered saline $(1 \mathrm{ml})$ and kept as a negative control group. Rabbits in other groups were IN infected with $2 \times 10^{5} \mathrm{CFU} / \mathrm{ml} /$ rabbit of $P$. multocida type $B$ at day 1 of the experiment [15]. Five days later (after appearance of clinical signs), group 3 rabbits were orally treated with allicin $50 \mathrm{mg} / \mathrm{kg}$ body weight for 5 days [16], group 4 rabbits received a single oral dose of norfloxacin (100 mg/kg body weight) [17], while group 5 rabbits were orally treated with a combination of norfloxacin and allicin in the same dose regimen used for groups 3 and 4.
2.5. Sample Collection and Preparation. Blood samples were collected at the end of the experiment (24hours after last dose) from the ear vein: $2 \mathrm{ml}$ of blood in a heparinized test tube for evaluation of phagocytic percent and index, $0.5 \mathrm{ml}$ in a test tube with the anticoagulant (EDTA) for hematological studies, and $5 \mathrm{ml}$ in a glass tube without anticoagulant for serum separation to assess biochemical parameters. The lung and liver tissues were dissected out after cervical dislocation, washed with physiological saline, and fixed with $10 \%$ neutral buffered formalin for histopathological examination.

2.6. Phagocytosis Assay. The heparinized blood samples of rabbits from different groups were used for leukocyte separation. Candida albicans (C. albicans) was prepared and used for evaluation of the phagocytic activity by the method of Wilkinson [18]. The number of macrophages (neutrophils and/or monocytes) containing C. albicans (phagocytic\%) that attached to or were ingested by 100 phagocytes in each individual preparation was determined by light microscopy. Moreover, the phagocytic index was calculated by determining the average number of attached and engulfed C. albicans multiplied by the phagocytic percent [19].

2.7. Hematological Indices. Blood samples, collected in tubes containing $10 \%$ EDTA solution, were used for determination of red blood cells (RBCs), hemoglobin ( $\mathrm{Hb}$ ), hematocrit/packed cell volume (HCT/PCV\%), white blood cells (WBC: leukogram), and differential leukocyte counts (DLC) according to Coles [20]. The mean corpuscle volume (MCV) and mean corpuscle hemoglobin concentration (MCHC) were calculated.

2.8. Biochemical Assay. Serum samples were analyzed for determination of alanine aminotransferase (ALT) by the method of Reitman and Frankel [21], alkaline phosphatase (ALP) according to Tietz [22], and lactate dehydrogenase (LDH) enzyme according to Buhl and Jackson [23]. The total protein and albumin levels were measured according to Doumas et al. [24] and Drupt [25], respectively. The globulin concentration was calculated by subtracting the obtained albumin concentration from the total protein concentration according to Doumas and Biggs [26].

2.9. Immunoglobulin and Cytokine Assay. The serum concentrations of immunoglobulin $\mathrm{G}$ (IgG) and immunoglobulin $\mathrm{M}$ (IgM) were determined using the commercial IgG and IgM ELISA kits, purchased from Bethyl Laboratories, USA (cat. no. E121-111, lot no. E121-111-150331, and cat. no. E120110, lot no. E120-110-29), respectively. The serum concentrations of tumor necrosis factor-alpha (TNF- $\alpha$ ) and interleukin6 (IL-6) were measured using standard kits obtained from Genorise (Nori ${ }^{\mathrm{TM}}$ Rabbit TNF- $\alpha$ ELISA Kit, cat. no. GRC144010) and CUSABIO (CSB-E06903Rb), respectively.

2.10. Estimation of Serum Oxidative Stress Markers. Serum samples were used to assay the reduced glutathione (GSH) level according to Jollow et al. [27], superoxide dismutase (SOD) activity according to Nishikimi et al. [28], and the lipid peroxidation marker (malondialdehyde (MDA)) 
depending on the thiobarbituric acid reactivity using the method of Ohkhawa et al. [29].

2.11. Histopathological Investigation. Specimens from the lungs and liver of different groups were collected and fixed in $10 \%$ neutral buffered formalin, transferred in ethanol (70\%), then cleared in xylene and embedded in paraffin. Five-micron-thick sections of paraffin were prepared then stained with hematoxylin and eosin dyes [30] and examined microscopically.

2.12. Statistical Analysis. All data were expressed as the mea $\mathrm{n} \pm$ standard error of mean (SEM) and were statistically analyzed by the SPSS/PC software (2001) using one-way analysis of variance (ANOVA), followed by post hoc Tukey's test. A $p$ value $<0.05$ was considered statistically significant.

\section{Results}

3.1. Clinical Signs and Mortality Rates. On the third day of the experiment, gp. 2 rabbits (infected but untreated) started to show the acute form of the disease (depression, reduced food intake, sneezing, conjunctivitis, respiratory distress, dyspnea, or even sudden death) with a mortality rate of $60 \%$. However, rabbits treated with allicin (gp.3) and norfloxacin (gp.4) showed less severe clinical signs than did gp.2 with mortality rates of 40 and $30 \%$, respectively. Rabbits treated with both allicin and norfloxacin (gp.5) were nearly healthy with much less severe clinical signs and a mortality rate of $10 \%$ till the time of scarification at the end of the experiment.

3.2. Erythrogram. At the end of experiment, there were significant decreases $(p<0.05)$ in RBC count, $\mathrm{Hb}$ concentration, PCV\%, and MCHC values, while MCV values exhibited a significant increase $(p<0.05)$ in rabbits infected with $P$. multocida (gp.2), compared to controls (gp.1). However, rabbits of gps.3, 4, and 5 showed non-significant changes in the RBCs count, $\mathrm{Hb}$ concentration, $\mathrm{PCV} \%, \mathrm{MCV}$, and $\mathrm{MCHC} \%$ except $\mathrm{Hb}$ concentration and $\mathrm{MCHC} \%$ showed significant increases in gp. 5 compared to gp.2 (Table 1).

3.3. Leukogram. The total leukocytic, neutrophil, and monocyte counts showed significant increases $(p<0.05)$ with a significant decrease $(p<0.05)$ in the lymphocytic count and non- significant changes in eosinophil count in P. multocidainfected rabbits (gp.2), compared to controls (gp.1). The treated gps. (3, and 5) showed a non significant decrease $(p<0.05)$ in the previous parameters except the neutrophil count, which showed a significant decrease $(p<0.05)$ while total leukocyte count that showed a significant decrease $(p$ $<0.05)$ in gp.5 compared to gp.2, while gp.4 showed a significant increases $(p<0.05)$ in the total leukocytic, neutrophil and eosinophil count with a non-significant changes in lymphocyte and monocyte counts compared to gp.2. The phagocytic activities (phagocytic\% and phagocytic index) were significantly increased $(p<0.05)$ in P. multocida-infected rabbits (gp.2) compared to controls. The treated rabbits (gps.3, 4, and 5) exhibited significant increases in both parameters $(p<0.05)$, compared to the infected nontreated group; however, none of these treatments could restore the normal range concentrations as in the control group (gp.1) (Table 1).

3.4. Biochemical Analysis. Table 2 shows the detailed changes in different biochemical parameters in control, infected, and treated groups. Moreover, serum immunoglobulin (IgG and IgM) levels showed significant decreases $(p<0.05)$ in gp.2, while gps.3, 4 , and 5 demonstrated significant increases $(p<0.05)$, compared to infected rabbits. The combination treatment restored the serum total protein concentration to the normal control level (as gp.1 rabbits).

3.5. Inflammatory Cytokines. Serum inflammatory cytokines (IL-6 and TNF- $\alpha$ ) showed significant increases $(p<0.05)$ in gp. 2 and significant decreases $(p<0.05)$ in the treated groups (4 and 5), except in the group receiving allicin (gp.3), which failed to improve serum TNF- $\alpha$ concentration, compared to infected nontreated rabbits (Table 2). The combination treatment could restore serum TNF- $\alpha$ concentration to normal control ranges (as gp. 1 rabbits).

3.6. Hepatic Enzymes. The serum activities of ALT, ALP, and LDH significantly increased $(p<0.05)$ in the P. multocidainfected group compared to controls and significantly decreased $(p<0.05)$ in treated groups $(3,4$, and 5$)$ compared to gp.2. The total, direct, and indirect bilirubin concentrations showed significant increases $(p<0.05)$ in infected rabbits; however, it exhibited significant reductions $(p<0.05)$ in the treated groups $(3,4$, and 5$)$, compared to infected nontreated rabbits (Table 3 ).

3.7. Antioxidant/Oxidative Stress Markers. Group 2 rabbits showed significant reductions in serum GSH and SOD levels $(p<0.05)$ with a significant increase $(p<0.05)$ in MDA serum concentration, compared to controls, while the treated rabbits (gps.3, 4, and 5) exhibited significant increases $(p<0.05)$ in GSH and SOD concentrations with a significant decrease $(p<0.05)$ in MDA concentration, compared to infected nontreated rabbits (Table 4).

3.8. Histopathological Findings. The lung tissue of normal control rabbits exhibited normal bronchial and bronchiolar structures with normal alveolar and perialveolar capillaries. On the other hand, lung tissue sections from Pasteurellainfected rabbits showed severe peribronchitis, congested blood vessels, vascular thrombi, and vasculitis. Diffuse interstitial inflammatory reaction, alveolar collapse, tissue destruction, and compensatory emphysema were also observed. On the other hand, infected rabbits, treated with allicin, showed mild to moderate lesions as mild congestion and leukocytic infiltration of interalveolar capillaries with mild emphysema of alveoli and focal necrotic lesions. Rabbits that received norfloxacin after infection had mild thickening of the interalveolar septa with inflammatory cells and congestion. Moreover, group V rabbits (which received the combination treatment) showed mild edema between alveoli with scanty inflammatory cells and no necrosis or tissue destruction (Figure 1).

The liver tissue of normal control rabbits showed eosinophilic radiating hepatic cords around central veins. The hepatic cells had abundant cytoplasm and large 
TABle 1: The effect of allicin, norfloxacin, and their combination treatment in Pasteurella multocida type B infection in male white New Zealand rabbits on hematological parameters.

\begin{tabular}{lccccc}
\hline Parameters & Control & Infected & $\begin{array}{c}\text { Groups } \\
\text { Infection + allicin }\end{array}$ & Infection + Nf & Infection + Nf + allicin \\
\hline RBCs $\left(10^{6} / \mathrm{mm}^{3}\right)$ & $4.51 \pm 0.04^{\mathrm{a}}$ & $3.63 \pm 0.09^{\mathrm{bc}}$ & $3.51 \pm 0.03^{\mathrm{bc}}$ & $3.43 \pm 0.04^{\mathrm{c}}$ & $3.58 \pm 0.06^{\mathrm{bc}}$ \\
$\mathrm{Hb}(\mathrm{g} / \mathrm{dl})$ & $8.68 \pm 0.05^{\mathrm{a}}$ & $6.56 \pm 0.7^{\mathrm{c}}$ & $6.64 \pm 0.12^{\mathrm{c}}$ & $6.44 \pm 0.07^{\mathrm{c}}$ & $6.96 \pm 0.08^{\mathrm{b}}$ \\
PCV\% & $36.40 \pm 0.65^{\mathrm{a}}$ & $31.98 \pm 0.52^{\mathrm{b}}$ & $31.56 \pm 0.66^{\mathrm{b}}$ & $30.78 \pm 0.19^{\mathrm{b}}$ & $31.20 \pm 0.31^{\mathrm{b}}$ \\
$\mathrm{MCV} / \mathrm{FL}$ & $80.58 \pm 0.76^{\mathrm{b}}$ & $90.02 \pm 1.18^{\mathrm{a}}$ & $89.85 \pm 2.21^{\mathrm{a}}$ & $89.55 \pm 0.79^{\mathrm{a}}$ & $87.14 \pm 1.65^{\mathrm{a}}$ \\
MCHC\% & $23.85 \pm 0.36^{\mathrm{a}}$ & $20.49 \pm 024^{\mathrm{c}}$ & $21.05 \pm 0.26^{\mathrm{c}}$ & $21.04 \pm 0.19^{\mathrm{c}}$ & $22.26 \pm 0.17^{\mathrm{b}}$ \\
WBCs $\left(10^{3} / \mathrm{mm}^{3}\right)$ & $6.35 \pm 0.06^{\mathrm{d}}$ & $7.35 \pm 0.12^{\mathrm{b}}$ & $7.15 \pm 0.07^{\mathrm{bc}}$ & $8.01 \pm 0.26^{\mathrm{a}}$ & $6.84 \pm 0.06^{\mathrm{c}}$ \\
Neutrophil $\left(10^{3} / \mathrm{mm}^{3}\right)$ & $1.31 \pm 0.01^{\mathrm{d}}$ & $3.41 \pm 0.08^{\mathrm{b}}$ & $3.00 \pm 0.08^{\mathrm{c}}$ & $3.82 \pm 0.14^{\mathrm{a}}$ & $2.87 \pm 0.03^{\mathrm{c}}$ \\
Eosinophil $\left(10^{3} / \mathrm{mm}^{3}\right)$ & $0.13 \pm 00^{\mathrm{c}}$ & $0.18 \pm 0.03^{\mathrm{bc}}$ & $0.17 \pm 0.04^{\mathrm{bc}}$ & $0.31 \pm 0.02^{\mathrm{a}}$ & $0.22 \pm 0.04^{\mathrm{b}}$ \\
Lymphocyte $\left(10^{3} / \mathrm{mm}^{3}\right)$ & $4.83 \pm 0.06^{\mathrm{a}}$ & $3.25 \pm 0.13^{\mathrm{bc}}$ & $3.53 \pm 0.12^{\mathrm{b}}$ & $3.42 \pm 0.08^{\mathrm{bc}}$ & $3.18 \pm 0.03^{\mathrm{c}}$ \\
Monocyte $\left(10^{3} / \mathrm{mm}^{3}\right)$ & $0.13 \pm 00^{\mathrm{b}}$ & $0.15 \pm 0.07^{\mathrm{a}}$ & $0.41 \pm 0.03^{\mathrm{a}}$ & $0.44 \pm 0.07^{\mathrm{a}}$ & $0.44 \pm 0.03^{\mathrm{a}}$ \\
Phagocytic\% & $41.8 \pm 0.49^{\mathrm{e}}$ & $53.00 \pm 0.32^{\mathrm{d}}$ & $58.2 \pm 0.200^{\mathrm{c}}$ & $64.60 \pm 0.400^{\mathrm{b}}$ & $76.4 \pm 0.51^{\mathrm{a}}$ \\
Phagocytic index & $0.34 \pm 0.01^{\mathrm{e}}$ & $0.53 \pm 0.01^{\mathrm{d}}$ & $0.59 \pm 0.003^{\mathrm{c}}$ & $0.65 \pm 0.013^{\mathrm{b}}$ & $0.84 \pm 0.005^{\mathrm{a}}$ \\
\hline
\end{tabular}

Values are represented as mean $\pm \operatorname{SEM}(n=10)$. Means within the same row carrying different superscripts $\left({ }^{\mathrm{a}},{ }^{\mathrm{b}},{ }^{\mathrm{c}}\right.$, and $\left.{ }^{\mathrm{d}}\right)$ are significant at $p<0.05$. Hb: hemoglobin; MCHC: mean corpuscle hemoglobin concentration; MCV: mean corpuscle volume; Nf: norfloxacin; PCV: packed cell volume; RBCs: red blood cells; WBCs: white blood cells.

TABle 2: The effect of allicin, norfloxacin, and their combination treatment in Pasteurella multocida type B infection in male white New Zealand rabbits on some biochemical parameters.

\begin{tabular}{lccccc}
\hline Parameter & Control & Infected & $\begin{array}{c}\text { Groups } \\
\text { Infection + allicin }\end{array}$ & Infection + NF & Infection + NF + allicin \\
\hline Total protein (g/dl) & $5.65 \pm 0.06^{\mathrm{a}}$ & $3.60 \pm 0.07^{\mathrm{c}}$ & $4.74 \pm 0.08^{\mathrm{b}}$ & $4.84 \pm 0.04^{\mathrm{b}}$ & $5.56 \pm 0.02^{\mathrm{a}}$ \\
Albumin (g/dl) & $3.99 \pm 0.06^{\mathrm{a}}$ & $2.50 \pm 0.06^{\mathrm{d}}$ & $3.33 \pm 0.06^{\mathrm{c}}$ & $3.28 \pm 0.05^{\mathrm{c}}$ & $3.58 \pm 0.04^{\mathrm{b}}$ \\
Globulin (g/dl) & $1.72 \pm 0.40^{\mathrm{b}}$ & $1.17 \pm 0.01^{\mathrm{e}}$ & $1.56 \pm 0.03^{\mathrm{c}}$ & $1.41 \pm 0.03^{\mathrm{d}}$ & $1.99 \pm 0.03^{\mathrm{a}}$ \\
IgM (mg/dl) & $26.00 \pm 0.77^{\mathrm{b}}$ & $13.80 \pm 0.80^{\mathrm{e}}$ & $19.60 \pm 0.81^{\mathrm{c}}$ & $16.6 \pm 0.81^{\mathrm{d}}$ & $33.80 \pm 0.80^{\mathrm{a}}$ \\
IgG (mg/dl) & $424.4 \pm 1.47^{\mathrm{b}}$ & $348.6 \pm 1.17^{\mathrm{e}}$ & $386.6 \pm 2.48^{\mathrm{c}}$ & $376.8 \pm 2.33^{\mathrm{d}}$ & $511.6 \pm 3.25^{\mathrm{a}}$ \\
IL-6 (pg/ml) & $224.80 \pm 1.46^{\mathrm{d}}$ & $325.00 \pm 2.07^{\mathrm{a}}$ & $250.00 \pm 0.84^{\mathrm{b}}$ & $243.60 \pm 1.66^{\mathrm{c}}$ & $246.00 \pm 2.43^{\mathrm{cb}}$ \\
TNF- $\alpha(\mathrm{pg} / \mathrm{ml})$ & $91.20 \pm 1.15^{\mathrm{c}}$ & $120.60 \pm 2.62^{\mathrm{a}}$ & $117.80 \pm 1.98^{\mathrm{a}}$ & $105.20 \pm 2.03^{\mathrm{b}}$ & $92.40 \pm 2.02^{\mathrm{c}}$ \\
\hline
\end{tabular}

Values are represented as mean $\pm \operatorname{SEM}(n=10)$. Means within the same row carrying different superscripts $\left({ }^{\mathrm{a}},{ }^{\mathrm{b}},{ }^{\mathrm{c}},{ }^{\mathrm{d}}\right.$, and $\left.{ }^{\mathrm{e}}\right)$ are significant at $p<0.05$. Ig: immunoglobulin; IL: interleukin; NF: norfloxacin; TNF: tumor necrosis factor.

TABle 3: The effect of allicin, norfloxacin, and their combination treatment in Pasteurella multocida type B infection in male white New Zealand rabbits on some hepatic markers.

\begin{tabular}{|c|c|c|c|c|c|}
\hline Parameters & Control & Infected & $\begin{array}{c}\text { Groups } \\
\text { Infection }+ \text { allicin }\end{array}$ & Infection $+\mathrm{NF}$ & Infection $+\mathrm{NF}+$ allicin \\
\hline$\overline{\mathrm{ALT}}(\mathrm{U} / \mathrm{L})$ & $34.2 \pm 1.06^{\mathrm{d}}$ & $48.20 \pm 0.20^{\mathrm{a}}$ & $37.4 \pm 0.87^{\mathrm{c}}$ & $44.00 \pm 0.44^{\mathrm{b}}$ & $37.20 \pm 1.07^{\mathrm{C}}$ \\
\hline $\operatorname{ALP}(\mathrm{U} / \mathrm{L})$ & $66.25 \pm 1.04^{\mathrm{c}}$ & $124.41 \pm 1.09^{\mathrm{a}}$ & $83.74 \pm 1.81^{\mathrm{b}}$ & $68.19 \pm 0.76^{\mathrm{C}}$ & $68.22 \pm 0.73^{c}$ \\
\hline $\mathrm{LDH}(\mathrm{U} / \mathrm{L})$ & $617.70 \pm 4.03^{\mathrm{d}}$ & $1105.63 \pm 2.25^{\mathrm{a}}$ & $800.56 \pm 24.22^{\mathrm{b}}$ & $683.74 \pm 4.84^{\mathrm{c}}$ & $646.44 \pm 1.61^{\mathrm{d}}$ \\
\hline Total bilirubin (mg/dl) & $1.27 \pm 0.004^{\mathrm{d}}$ & $3.04 \pm 0.004^{\mathrm{a}}$ & $1.93 \pm 0.024^{\mathrm{b}}$ & $1.58 \pm 0.124^{\mathrm{c}}$ & $1.40 \pm 0.044^{\mathrm{d}}$ \\
\hline Direct bilirubin (mg/dl) & $0.36 \pm 0.014^{\mathrm{d}}$ & $1.14 \pm 0.029^{\mathrm{a}}$ & $0.81 \pm 0.013^{\mathrm{b}}$ & $0.54 \pm 0.040^{\mathrm{C}}$ & $0.31 \pm 0.002^{\mathrm{d}}$ \\
\hline Indirect bilirubin (mg/dl) & $0.91 \pm 0.015^{\mathrm{c}}$ & $1.90 \pm 0.032^{\mathrm{a}}$ & $1.12 \pm 0.025^{\mathrm{b}}$ & $1.04 \pm 0.115^{\mathrm{bc}}$ & $1.09 \pm 0.043^{\mathrm{bc}}$ \\
\hline
\end{tabular}

Values are represented as mean $\pm \operatorname{SEM}(n=10)$. Means within the same row carrying different superscripts $\left({ }^{\mathrm{a}},{ }^{\mathrm{b}},{ }^{\mathrm{c}}\right.$, and $\left.{ }^{\mathrm{d}}\right)$ are significant at $p<0.05$. ALP: alkaline phosphatase; ALT: alanine transferase; LDH: lactate dehydrogenase; NF: norfloxacin.

centrally located nuclei. In contrast, liver sections from rabbits, infected with Pasteurella, demonstrated severe congestion of hepatic blood vessels along with perivascular edema, diffuse degeneration of hepatocytes, and focal necrosis. Infected rabbits, treated with allicin, showed diffuse vacuolar degeneration and mild to moderate congestion of blood vessels. Rabbits that received norfloxacin after infection had focal areas of degeneration with mild congestion of blood vessels. Further, sections from infected rabbits receiving the combination treatment showed fairly normal hepatic cords with focal-to-discrete hepatocytes suffering mild vacuolar degeneration (Figure 2). 
TABLE 4: The effect of allicin, norfloxacin, and their combination treatment in Pasteurella multocida type B infection in male white New Zealand rabbits on oxidative stress markers.

\begin{tabular}{lccccc}
\hline Parameters & Control & Infected & $\begin{array}{c}\text { Groups } \\
\text { Infection + allicin }\end{array}$ & Infection + NF & Infection + allicin + NF \\
\hline GSH (mmol/L) & $0.67 \pm 0.02^{\mathrm{a}}$ & $0.19 \pm 0.01^{\mathrm{d}}$ & $0.37 \pm 0.03^{\mathrm{c}}$ & $0.50 \pm 0.03^{\mathrm{b}}$ & $0.62 \pm 0.02^{\mathrm{a}}$ \\
SOD (U/ml) & $4.90 \pm 0.15^{\mathrm{a}}$ & $2.16 \pm 0.09^{\mathrm{c}}$ & $3.4 \pm 0.17^{\mathrm{b}}$ & $3.31 \pm 0.14^{\mathrm{b}}$ & $4.55 \pm 0.09^{\mathrm{a}}$ \\
MDA (nmol/ml) & $38.19 \pm 0.44^{\mathrm{d}}$ & $62.75 \pm 1.32^{\mathrm{a}}$ & $48.45 \pm 0.83^{\mathrm{b}}$ & $41.00 \pm 1.08^{\mathrm{c}}$ & $34.65 \pm 0.68^{\mathrm{e}}$ \\
\hline
\end{tabular}

Values are represented as mean $\pm \operatorname{SEM}(n=10)$. Means within the same row carrying different superscripts $\left({ }^{\mathrm{a}},{ }^{\mathrm{b}},{ }^{\mathrm{c}},{ }^{\mathrm{d}}\right.$, and $\left.{ }^{\mathrm{e}}\right)$ are significant at $p<0.05$. GSH: glutathione; MDA: malondialdehyde; NF: norfloxacin; SOD: superoxide dismutase

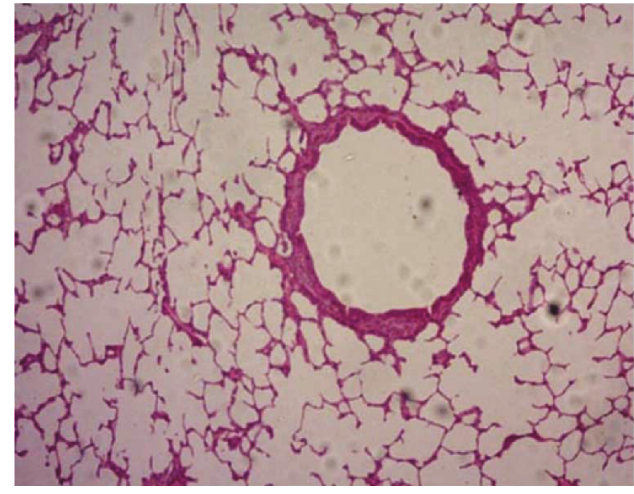

(a)

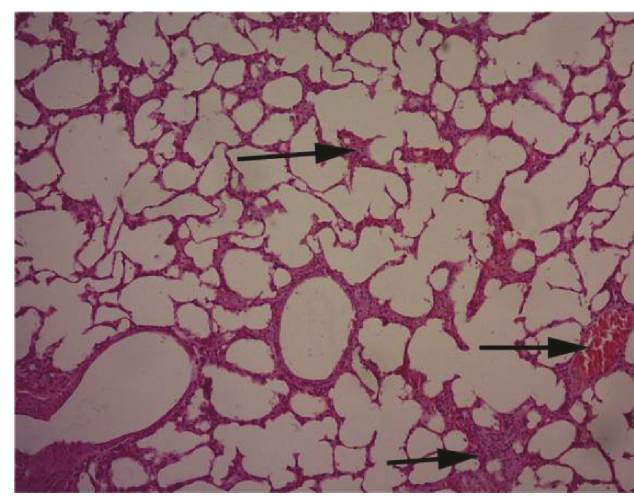

(c)

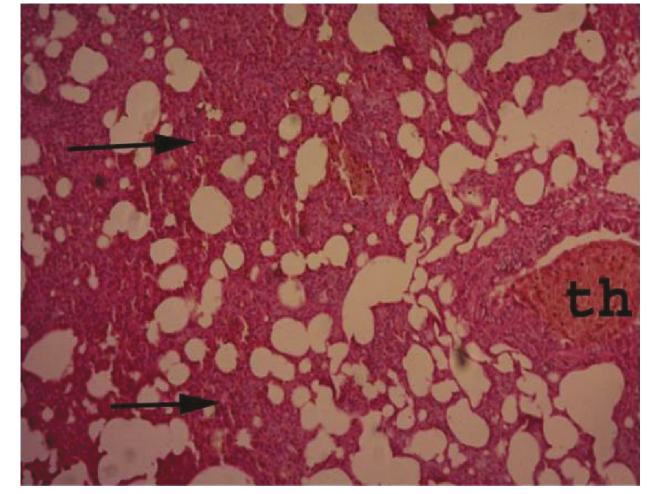

(b)

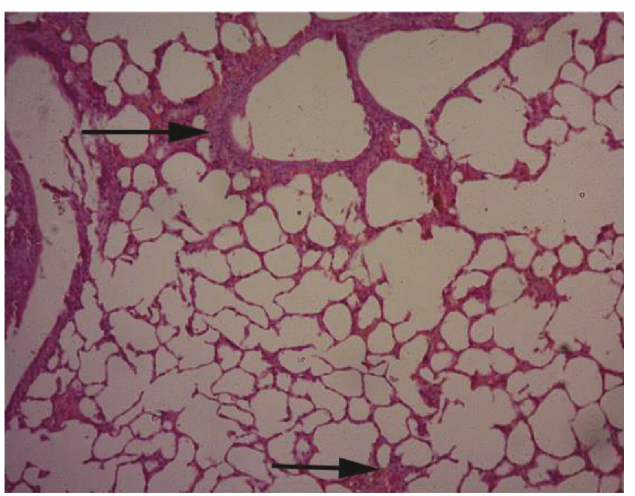

(d)

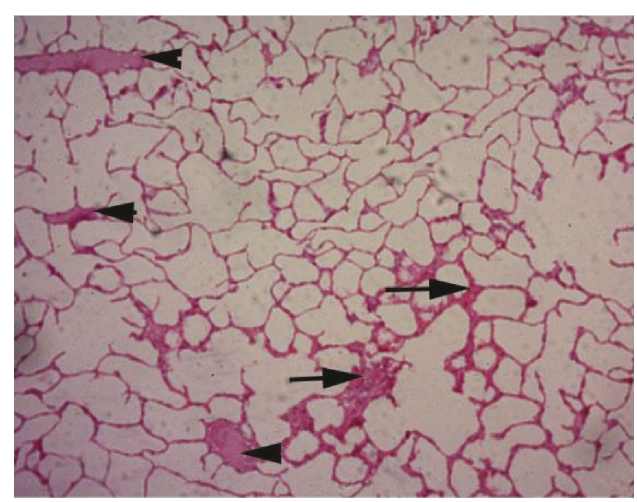

(e)

FIGURE 1: Shows lung sections from (a) normal control animals, (b) Pasteurella-infected group showing interstitial inflammatory reaction, (c) allicin-treated rabbits, (d) norfloxacin-treated rabbits, and (e) infected rabbits, treated with allicin-norfloxacin combination. Arrows refer to thickening of interstitial tissue with dilated capillaries and leucocytes, and arrowheads refer to edema. Hematoxylin and eosin stain; magnification: 100x. 


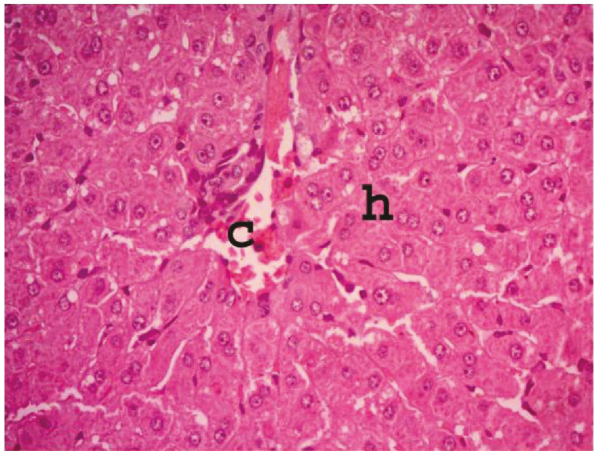

(a)

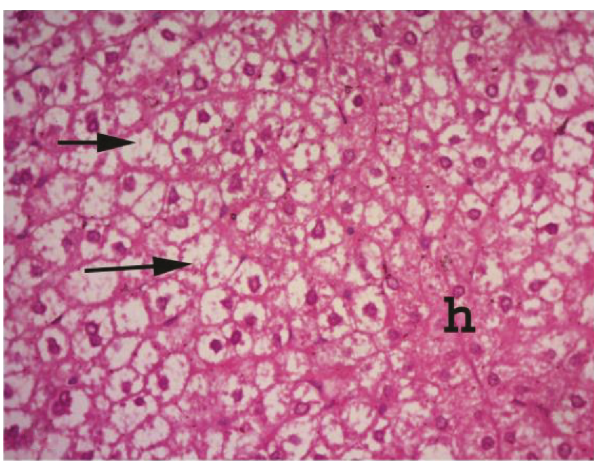

(c)

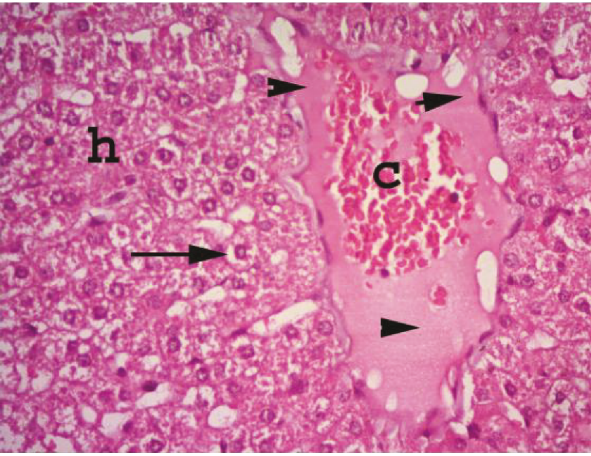

(b)

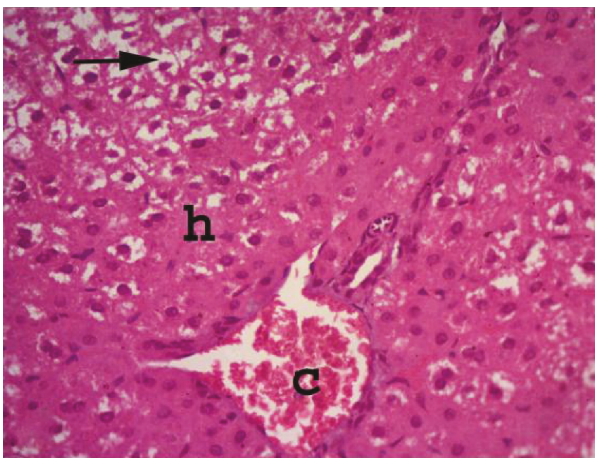

(d)

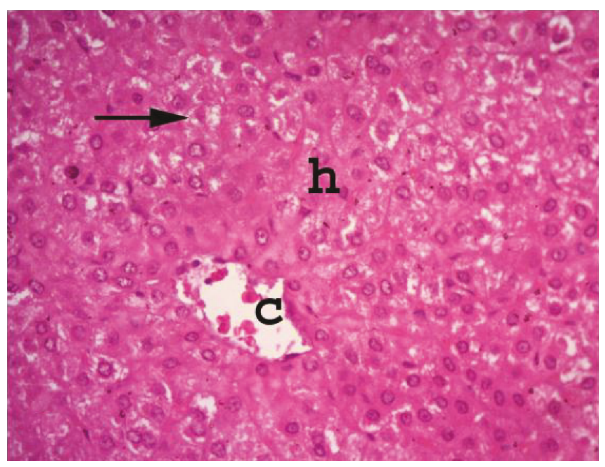

(e)

Figure 2: Shows liver sections from (a) normal control animals; (b) Pasteurella-infected group showing degeneration, necrosis of hepatocytes, and severe congestion of blood vessels; (c) allicin-treated rabbits; (d) norfloxacin-treated rabbits; and (e) infected rabbits, treated with allicin and norfloxacin combination. Arrows refer to thickening of interstitial tissue with dilated capillaries and leucocytes, and arrowheads refer to edema. Hematoxylin and eosin stain; magnification: 100x.

\section{Discussion}

Rabbit husbandry requires good environmental conditions to reduce infection risks. Sneezing, nasal discharge, respiratory distress, and conjunctivitis were the common signs of $P$. multocida type B infection, observed in this study. Moreover, we detected frequent abscess formation in the lung tissue, bronchopneumonia, and septicemia, which may have been the main causes of morbidity and mortality in rabbits [31, 32]. Our results are in agreement with those of previous studies by Martino and Luzi [7], Palócz et al. [33], and Katoch et al. [15].

Allicin-treated rabbits exhibited less severe clinical signs and a lower mortality rate, probably related to the antibacterial and anti-inflammatory activities of allicin $[34,35]$. Moreover, allicin was reported to scavenge free radicals and to inhibit the cysteine protease and thiol-containing protein in bacterial cells, inhibiting their growth $[36,37]$. Similarly, infected rabbits treated with norfloxacin $(100 \mathrm{mg} / \mathrm{kg})$ showed marked reductions in the mortality rate and severity of clinical signs [38], probably due to the strong antibacterial activity of norfloxacin [39]. Interestingly, there was a marked reduction in the clinical signs and mortality rate in nearly all infected rabbits in the allicin-norfloxacin combination group, compared to either treatment alone.

Rabbits, infected with P. multocida, exhibited macrocytic hypochromic anemia (reticulocytosis), probably due to enhanced erythropoiesis as a response of the bone marrow 
to the increased blood loss in trachea-pulmonary hemorrhage, caused by septicemia [40]. Our results agree with those by Nassar et al. [41] who reported that there was a significant reduction in RBC count and PCV\% in P. multocida-infected rabbits. Rabbits treated with a combination of allicin and norfloxacin showed an improvement in the picture of anemia, especially $\mathrm{Hb}$ level, which reflects reduction of the bacterial toxic effect on the bone marrow with decreasing or stopping the hemorrhage. The leukogram investigation revealed leukocytosis with heterophilia, and monocytosis in the $P$. multocida-infected group, which can be attributed to the body inflammatory response [40]; leukocytes were elevated in our study to overcome infection as they are the first line of the body's defense mechanism against any pathogenic agents.

Infections with $P$. multocida are usually associated with leukocytosis as a physiological response from the body to minimize the spread of infection [41-43]. Lymphopenia occurred in this study probably due to increased cytolysis produced by bacterial toxin and lymphocyte drainage into the infected tissues [44]. In contrast, rabbits treated with allicin alone showed a significant elevation in leukocyte count, reflecting the antibacterial and antitoxic effects of allicin [45]. Neutrophils showed a significant increase after allicin and/or norfloxacin treatment which may be a response to the increased serum concentrations of IL- 6 and TNF- $\alpha$ [46-48].

The cellular immune response in the body increases physiologically in case of infection to destroy infective agents and minimize the spread of infection [42]. This study revealed a significant elevation in the phagocytic activity (phagocytic percent and phagocytic index) in $P$. multocida-infected rabbits. In agreement with El-Deeb and Elmoslemany [49], proinflammatory cytokines' serum levels (TNF- $\alpha$ and IL-6) were markedly elevated to enhance leukocyte migration into the infection site [46-48]. It has been reported that IL-6 increases in the blood after infection as an inflammatory response to regulate neutrophil and monocyte transition during the inflammation process $[50,51]$.

Allicin treatment significantly increased the phagocytic activity in infected rabbits, probably due to the ability of allicin to modulate the peripheral leukocytes' immune functions [52] through stimulating the proliferation of immune cells, lysozyme activities, and oxidative burst $[53,54]$, as well as enhancing the proinflammatory mediators like interferongamma and the expansion of $\mathrm{CD} 4^{+} \mathrm{T}$ cells [55]. Furthermore, allicin markedly alleviates the inflammation through reducing the production of TNF- $\alpha$ and IL-6 [56-58]. The antibacterial and anti-inflammatory effects of allicin may be explained by modulation of the cytokines and activating macrophages that controlled the infection.

Hypoproteinemia and hypoglobulinemia were observed in $P$. multocida-infected rabbits, which may be due to protein loss during hemorrhage. Anorexia and fever that result from the infection lead to increased protein catabolism and reduced protein synthesis by degenerated hepatocytes [33]. Allicin-treated groups showed significant improvements in serum protein and albumin levels, indicating the attenuation of hepatic injury and inflammation induced by $P$. multocida infection [35], hemorrhage reduction, and improvement of the animals' appetite.
Allicin-treated groups had an elevation in globulin, IgG, and IgM serum levels, reflecting the increased production of Igs from lymphoid organs to opsonize the P. multocida bacteria and limit the systemic infection [59]. It has been reported that allicin significantly enhances the immune response during infection through elevation of Ig levels [60]. Similarly, norfloxacin was an effective antibacterial agent, able to improve the protein, albumin, globulin, and Ig levels in infected rabbits.

Regarding enzyme activities and liver functions, ALT, ALP, LDH, and bilirubin showed significant elevations in Pasteurella-infected rabbits, possibly related to injury and degeneration of hepatocytes [61-63]. However, infected rabbits, treated with allicin and/or norfloxacin, showed marked reductions in serum ALT, ALP, LDH, and bilirubin levels, confirming the antibacterial activity of allicin and norfloxacin that reduced the damaging effects of bacteria on the liver [64].

Rabbits, infected with P. multocida, showed marked reductions in serum GSH and SOD with elevation of MDA levels, reflecting the increased lipid peroxidation and production of reactive oxygen species by bacterial infection [49]. Our results indicate that allicin treatment, alone or in combination with norfloxacin, ameliorated the oxidative stress and generation of free radicals in the infected rabbits represented by amelioration of lipid peroxidation and elevation of GSH and SOD levels through its antioxidative action $[58,65,66]$. Several garlic components, including allicin and selenium, have been shown able to attenuate the signaling pathways of reactive oxygen species and increase the endogenous antioxidant enzymatic activity [67-69]. Treatment with norfloxacin, alone or in combination with allicin, improved the antioxidant state and reduced the infection-induced oxidative stress.

\section{Conclusion}

The results of this study show that the clinically observed damage in rabbits infected with $P$. multocida can be ameliorated by allicin administration, probably through its antioxidant, anti-inflammatory, and immunostimulant effects. This protective effect could reduce the use of antibiotic in pets and livestock, reducing human exposure to antibiotic residues and bacterial resistance to antibiotics. Further, norfloxacin can be used for the effective treatment of pasteurellosis in rabbits. The combination of allicin and norfloxacin was more powerful in improving the $P$. multocida-induced alterations than each treatment alone.

\section{Abbreviations}

ALP: Alkaline phosphatase

ALT: Alanine transferase

GSH: Glutathione

Hb: Hemoglobin

IL: Interleukin

IN: Intranasal

LDH: Lactate dehydrogenase

MCHC: Mean corpuscle hemoglobin concentration 
MCV: Mean corpuscle volume

MDA: Malondialdehyde

PCV: $\quad$ Packed cell volume

SOD: $\quad$ Superoxide dismutase

TNF: Tumor necrosis factor.

\section{Data Availability}

The data used to support the findings of this study are available from the corresponding author upon request.

\section{Conflicts of Interest}

The authors declare that they have no conflict of interest.

\section{References}

[1] F. Dziva, A. P. Muhairwa, M. Bisgaard, and H. Christensen, "Diagnostic and typing options for investigating diseases associated with Pasteurella multocida," Veterinary Microbiology, vol. 128, no. 1-2, pp. 1-22, 2008.

[2] G. P. Langan, J. J. Lohmiller, S. P. Swing, and C. L. Wardrip, "Respiratory diseases of rodents and rabbits," Veterinary Clinics of North America: Small Animal Practice, vol. 30, no. 6, pp. 1309-1335, 2000.

[3] S. Sanchez, S. Mizan, C. Quist et al., "Serological response to Pasteurella multocida NanH sialidase in persistently colonized rabbits," Clinical and Vaccine Immunology, vol. 11, no. 5, pp. 825-834, 2004.

[4] P. B. Fernandes, "Mode of action, and in vitro and in vivo activities of the fluoroquinolones," The Journal of Clinical Pharmacology, vol. 28, no. 2, pp. 156-168, 1988.

[5] M. P. Wentland, "Structure-activity relationships of fluoroquinolones," The New Generation of Quinolones, pp. 1-43, 1990.

[6] T. A. Ahmad, S. S. Rammah, S. A. Sheweita, M. Haroun, and L. H. El-Sayed, "Development of immunization trials against Pasteurella multocida," Vaccine, vol. 32, no. 8, pp. 909-917, 2014.

[7] P. Martino and F. Luzi, Bacterial Infections in Rabbit as Companion Animal: A Survey of Diagnostic Samples in Italy, 9th World Rabbit Congress, Verona-Italy, 2008.

[8] M. K. Fann and D. O'Rourke, "Normal bacterial flora of the rabbit gastrointestinal tract: a clinical approach," Seminars in Avian and Exotic Pet Medicine, vol. 10, no. 1, pp. 45-47, 2001.

[9] T. H. Abdullah, O. Kandil, A. Elkadi, and J. Carter, "Garlic revisited: therapeutic for the major diseases of our times?," Journal of the National Medical Association, vol. 80, no. 4, pp. 439-445, 1988.

[10] S. K. Banerjee, P. K. Mukherjee, and S. K. Maulik, "Garlic as an antioxidant: the good, the bad and the ugly," Phytotherapy Research, vol. 17, no. 2, pp. 97-106, 2003.

[11] M. S. Butt, M. T. Sultan, M. S. Butt, and J. Iqbal, "Garlic: nature's protection against physiological threats," Critical Reviews in Food Science and Nutrition, vol. 49, no. 6, pp. 538-551, 2009.

[12] E. H. Abu Zeid, R. T. M. Alam, and N. E. Abd El-Hameed, "Impact of titanium dioxide on androgen receptors, seminal vesicles and thyroid hormones of male rats: possible protective trial with aged garlic extract," Andrologia, vol. 49, no. 5, 2017.

[13] M. M. Abdel-Daim, N. K. M. Abdelkhalek, and A. M. Hassan, "Antagonistic activity of dietary allicin against deltamethrin- induced oxidative damage in freshwater Nile tilapia; Oreochromis niloticus," Ecotoxicology and Environmental Safety, vol. 111, pp. 146-152, 2015.

[14] M. M. Abdel-Daim, O. E. Kilany, H. A. Khalifa, and A. A. M. Ahmed, "Allicin ameliorates doxorubicin-induced cardiotoxicity in rats via suppression of oxidative stress, inflammation and apoptosis," Cancer Chemotherapy and Pharmacology, vol. 80, no. 4, pp. 745-753, 2017.

[15] S. Katoch, L. Verma, M. Sharma et al., "Experimental study of the pathogenicity of pasteurella multocida capsular type B in rabbits," Journal of Comparative Pathology, vol. 153, no. 2-3, pp. 160-166, 2015.

[16] X.-H. Li, C.-Y. Li, Z.-G. Xiang et al., “Allicin ameliorates cardiac hypertrophy and fibrosis through enhancing of Nrf2 antioxidant signaling pathways," Cardiovascular Drugs and Therapy, vol. 26, no. 6, pp. 457-465, 2012.

[17] B. Pavithra, N. Prakash, and K. Jayakumar, "PK-PD modelling of norfloxacin after oral administration in rabbits," Veterinary World, vol. 3, no. 12, pp. 546-548, 2010.

[18] P. C. Wilkinson, Technique in Clinical Immunology, R. A. Thompson, Ed., Publication, USA, 1977.

[19] M. I. Muniz-Junqueira, C. E. Tosta, and A. Prata, "Phagocytic and bactericidal function of mouse macrophages to Salmonella typhimurium in schistosomiasis mansoni," The American Journal of Tropical Medicine and Hygiene, vol. 46, no. 2, pp. 132-136, 1992.

[20] E. H. Coles, Veterinary Clinical Pathology: Saunders, W.B. Saunders Company, Philadelphia, PA, USA, 4th edition, 1986.

[21] S. Reitman and S. Frankel, "A colorimetric method for the determination of serum glutamic oxalacetic and glutamic pyruvic transaminases," American Journal of Clinical Pathology, vol. 28, no. 1, pp. 56-63, 1957.

[22] N. W. Tietz, Clinical Guide to Laboratory Tests, W. B. Saunders, Philadelphia, PA, USA, 3rd edition, 1995.

[23] S. Buhl and K. Jackson, "Optimal conditions and comparison of lactate dehydrogenase catalysis of the lactate-to-pyruvate and pyruvate-to-lactate reactions in human serum at 25, 30, and 37 degrees C," Clinical Chemistry, vol. 24, no. 5, pp. 828-831, 1978.

[24] B. T. Doumas, D. D. Bayse, R. J. Carter, T. Peters Jr, and R. Schaffer, "A candidate reference method for determination of total protein in serum. I. Development and validation," Clinical Chemistry, vol. 27, no. 10, pp. 1642-1650, 1981.

[25] F. Drupt, "Colorimetric determination of albumin," Pharmaceutical Biology, vol. 9, p. 777, 1974.

[26] B. B. H. Doumas, "Determination of serumglobulin," in Standard Methods of Clinical Chemistry, Academic Press, New York, 7th edition, 1972.

[27] D. J. Jollow, J. R. Mitchell, N. Zampaglione, and J. R. Gillette, "Bromobenzene-induced liver necrosis. Protective role of glutathione and evidence for 3, 4-bromobenzene oxide as the hepatotoxic metabolite," Pharmacology, vol. 11, no. 3, pp. 151-169, 1974.

[28] M. Nishikimi, N. Appaji Rao, and K. Yagi, "The occurrence of superoxide anion in the reaction of reduced phenazine methosulfate and molecular oxygen," Biochemical and Biophysical Research Communications, vol. 46, no. 2, pp. 849-854, 1972.

[29] H. Ohkawa, N. Ohishi, and K. Yagi, “Assay for lipid peroxides in animal tissues by thiobarbituric acid reaction," Analytical Biochemistry, vol. 95, no. 2, pp. 351-358, 1979. 
[30] K. S. Suvarna, C. Layton, and J. D. Bancroft, Bancroft's Theory and Practice of Histological Techniques E-Book: Elsevier Health Sciences, Elsevier Health Sciences, Churchill Livingstone, Australia, 7th edition, 2012.

[31] R. F. DiGiacomo, B. J. Deeb, W. E. Giddens Jr, B. L. Bernard, and M. M. Chengappa, "Atrophic rhinitis in New Zealand white rabbits infected with Pasteurella multocida," American Journal of Veterinary Research, vol. 50, no. 9, pp. 1460-1465, 1989.

[32] T. Zimmerman, B. Deeb, and R. DiGiacomo, "Polypeptides associated with Pasteurella multocida infection in rabbits," American Journal of Veterinary Research, vol. 53, no. 7, pp. 1108-1112, 1992.

[33] O. Palócz, J. Gál, P. Clayton et al., "Alternative treatment of serious and mild Pasteurella multocida infection in New Zealand White rabbits," BMC Veterinary Research, vol. 10, no. 1, p. 276, 2014.

[34] S. Ankri and D. Mirelman, "Antimicrobial properties of allicin from garlic," Microbes and Infection, vol. 1, no. 2, pp. 125-129, 1999.

[35] M. A. Dkhil, A. S. Abdel-Baki, F. Wunderlich, H. Sies, and S. Al-Quraishy, "Anticoccidial and antiinflammatory activity of garlic in murine Eimeria papillata infections," Veterinary Parasitology, vol. 175, no. 1-2, pp. 66-72, 2011.

[36] S. Ankri, T. Miron, A. Rabinkov, M. Wilchek, and D. Mirelman, "Allicin from garlic strongly inhibits cysteine proteinases and cytopathic effects of Entamoeba histolytica," Antimicrobial Agents and Chemotherapy, vol. 41, no. 10, pp. 2286-2288, 1997.

[37] A. Coppi, M. Cabinian, D. Mirelman, and P. Sinnis, "Antimalarial activity of allicin, a biologically active compound from garlic cloves," Antimicrobial Agents and Chemotherapy, vol. 50, no. 5, pp. 1731-1737, 2006.

[38] S. R. Norrby and M. Jonsson, "Antibacterial activity of norfloxacin," Antimicrobial Agents and Chemotherapy, vol. 23, no. 1, pp. 15-18, 1983.

[39] J. S. Wolfson and D. C. Hooper, "Norfloxacin: a new targeted fluoroquinolone antimicrobial agent," Annals of Internal Medicine, vol. 108, no. 2, pp. 238-251, 1988.

[40] B. F. Z. J. G. Feldman and V. C. Jain, Schalm's Veterinary Hematology, Lippincott Williams and Wilkins, Philadilphia, 5th edition, 2000.

[41] S. A. Nassar, A. H. Mohamed, H. Soufy, and S. M. Nasr, "Protective effect of Egyptian propolis against rabbit pasteurellosis," BioMed Research International, vol. 2013, Article ID 163724, 9 pages, 2013.

[42] Y. Watanabe, "Five cases of respiratory infection due to Pasteurella multocida," Journal of the Japanese Association for Infectious Diseases, vol. 67, no. 12, pp. 1228-1232, 1993.

[43] R. P. Ruble, J. S. Cullor, and D. L. Brooks, "The observation of reactive thrombocytosis in New Zealand white rabbits in response to experimental Pasteurella multocida infection," Blood Cells, Molecules, and Diseases, vol. 25, no. 2, pp. 95-102, 1999.

[44] P. E. Praveena, N. Singh, S. Periasamy, and A. Kumar, "Studies on haematobiochemical changes in Pasteurella multocida serotype A1 infection in mice," Indian Journal of Veterinary Pathology, vol. 31, pp. 155-159, 2007.

[45] R. R. Cutler and P. Wilson, "Antibacterial activity of a new, stable, aqueous extract of allicin against methicillin-resistant
Staphylococcus aureus," British Journal of Biomedical Science, vol. 61, no. 2, pp. 71-74, 2004.

[46] D. C. Morrison, R. Silverstein, M. Luchi, and A. Shnyra, "Structure-function relationships of bacterial endotoxins: contribution to microbial sepsis," Infectious Disease Clinics of North America, vol. 13, no. 2, pp. 313-340, 1999.

[47] O. Yoshie, T. Imai, and H. Nomiyama, "Chemokines in immunity," Advances in Immunology, vol. 78, pp. 57-110, 2001.

[48] J.C. Hodgson, "Endotoxin and mammalian host responses during experimental disease," Journal of Comparative Pathology, vol. 135, no. 4, pp. 157-175, 2006.

[49] W. M. El-Deeb and A. M. Elmoslemany, "The diagnostic accuracy of acute phase proteins and proinflammatory cytokines in sheep with pneumonic pasteurellosis," PeerJ, vol. 4, article e2161, 2016.

[50] G. Kaplanski, V. Marin, F. Montero-Julian, A. Mantovani, and C. Farnarier, "IL-6: a regulator of the transition from neutrophil to monocyte recruitment during inflammation," Trends in Immunology, vol. 24, no. 1, pp. 25-29, 2003.

[51] P. E. Praveena, S. Periasamy, A. A. Kumar, and N. Singh, "Cytokine profiles, apoptosis and pathology of experimental Pasteurella multocida serotype A1 infection in mice," Research in Veterinary Science, vol. 89, no. 3, pp. 332-339, 2010.

[52] H. Salman, M. Bergman, H. Bessler, I. Punsky, and M. Djaldetti, "Effect of a garlic derivative (alliin) on peripheral blood cell immune responses," International Journal of Immunopharmacology, vol. 21, no. 9, pp. 589-597, 1999.

[53] E. J. Nya and B. Austin, "Use of garlic, Allium sativum, to control Aeromonas hydrophila infection in rainbow trout, Oncorhynchus mykiss (Walbaum)," Journal of Fish Diseases, vol. 32, no. 11, pp. 963-970, 2009.

[54] E. J. Nya, Z. Dawood, and B. Austin, "The garlic component, allicin, prevents disease caused by Aeromonas hydrophila in rainbow trout, Oncorhynchus mykiss (Walbaum)," Journal of Fish Diseases, vol. 33, no. 4, pp. 293-300, 2010.

[55] Y. Feng, X. Zhu, Q. Wang et al., "Allicin enhances host proinflammatory immune responses and protects against acute murine malaria infection," Malaria Journal, vol. 11, no. 1, p. 268, 2012.

[56] R. Bruck, H. Aeed, E. Brazovsky, T. Noor, and R. Hershkoviz, "Allicin, the active component of garlic, prevents immunemediated, concanavalin A-induced hepatic injury in mice," Liver International, vol. 25, no. 3, pp. 613-621, 2005.

[57] A. Makris, C. E. Thornton, B. Xu, and A. Hennessy, "Garlic increases IL-10 and inhibits TNF $\alpha$ and IL- 6 production in endotoxin-stimulated human placental explants," Placenta, vol. 26, no. 10, pp. 828-834, 2005.

[58] A. R. El-Sheakh, H. A. Ghoneim, G. M. Suddek, and E. S. M. Ammar, "Attenuation of oxidative stress, inflammation, and endothelial dysfunction in hypercholesterolemic rabbits by allicin," Canadian Journal of Physiology and Pharmacology, vol. 94, no. 2, pp. 216-224, 2016.

[59] E. Kyo, N. Uda, S. Kasuga, and Y. Itakura, "Immunomodulatory effects of aged garlic extract," The Journal of Nutrition, vol. 131, no. 3, pp. 1075S-1079S, 2001.

[60] R. O. A. Kamel and N. A. El-Shinnawy, "Immunomodulatory effect of garlic oil extract on Schistosoma mansoni infected mice," Asian Pacific Journal of Tropical Medicine, vol. 8, no. 12, pp. 999-1005, 2015.

[61] Z. Jaglic, E. Jeklova, H. Christensen et al., "Host response in rabbits to infection with Pasteurella multocida serogroup $\mathrm{F}$ 
strains originating from fowl cholera," Canadian Journal of Veterinary Research, vol. 75, no. 3, pp. 200-208, 2011.

[62] E. M. Leise, I. Gray, and M. K. Ward, "Leukocyte lactate dehydrogenase changes as an indicator of infection prior to overt symptoms," Journal of Bacteriology, vol. 96, no. 1, pp. 154-159, 1968.

[63] E. M. Leise, F. LeSane, and I. Gray, "Lymphocyte and polymorphonuclear enzymes in stress: IV. Changes associated with an acute bacterial infection with Diplococcus pneumoniae," Biochemical Medicine, vol. 9, no. 3, pp. 206-213, 1974.

[64] W. Abu El Hammed, H. Soufy, A. El-Shemy, S. M. Nasr, and M. I. Dessouky, "Use of allicin as feed additive to enhance vaccination capacity of Clostridium perfringens toxoid in rabbits," Vaccine, vol. 34, no. 17, pp. 2000-2007, 2016.

[65] Y. Okada, K. Tanaka, E. Sato, and H. Okajima, "Kinetic and mechanistic studies of allicin as an antioxidant," Organic \& Biomolecular Chemistry, vol. 4, no. 22, pp. 4113-4117, 2006.

[66] L. Horev-Azaria, S. Eliav, N. Izigov et al., "Allicin up-regulates cellular glutathione level in vascular endothelial cells," European Journal of Nutrition, vol. 48, no. 2, pp. 67-74, 2009.

[67] A. I. Abushouk, A. Ismail, A. M. A. Salem, A. M. Afifi, and M. M. Abdel-Daim, "Cardioprotective mechanisms of phytochemicals against doxorubicin-induced cardiotoxicity," Biomedicine \& Pharmacotherapy, vol. 90, pp. 935-946, 2017.

[68] J.-W. Zhu, T. Chen, J. Guan, W.-B. Liu, and J. Liu, "Neuroprotective effects of allicin on spinal cord ischemia-reperfusion injury via improvement of mitochondrial function in rabbits," Neurochemistry International, vol. 61, no. 5, pp. 640-648, 2012.

[69] S. Shaban, M. W. A. El-Husseny, A. I. Abushouk, A. M. A. Salem, M. Mamdouh, and M. M. Abdel-Daim, "Effects of antioxidant supplements on the survival and differentiation of stem cells," Oxidative Medicine and Cellular Longevity, vol. 2017, Article ID 5032102, 16 pages, 2017. 


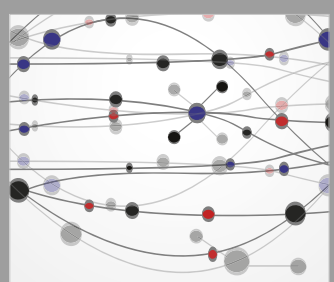

The Scientific World Journal
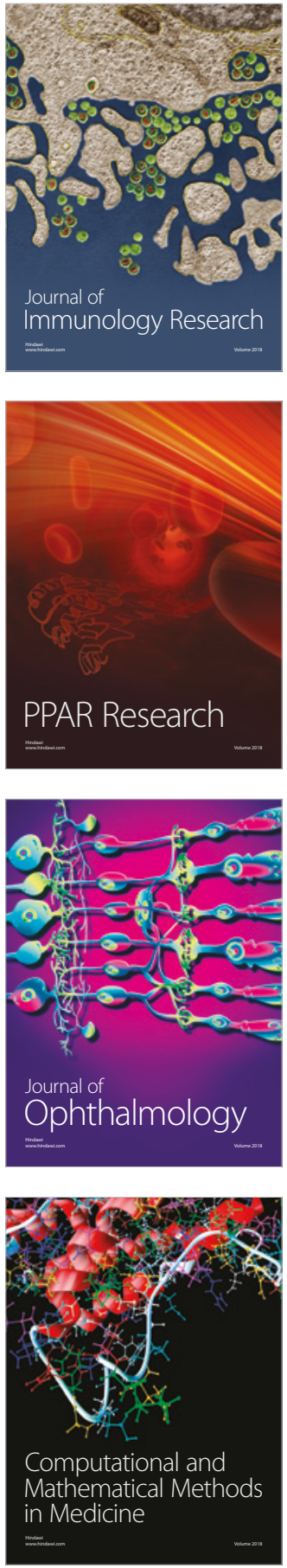

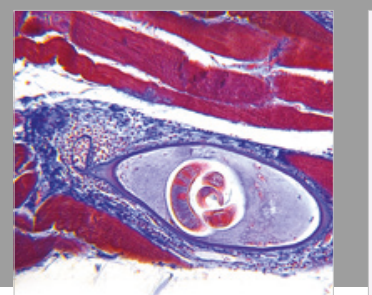

Gastroenterology Research and Practice

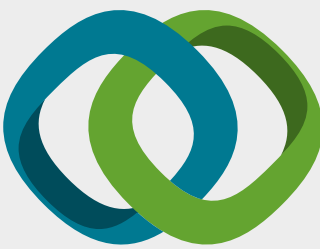

\section{Hindawi}

Submit your manuscripts at

www.hindawi.com
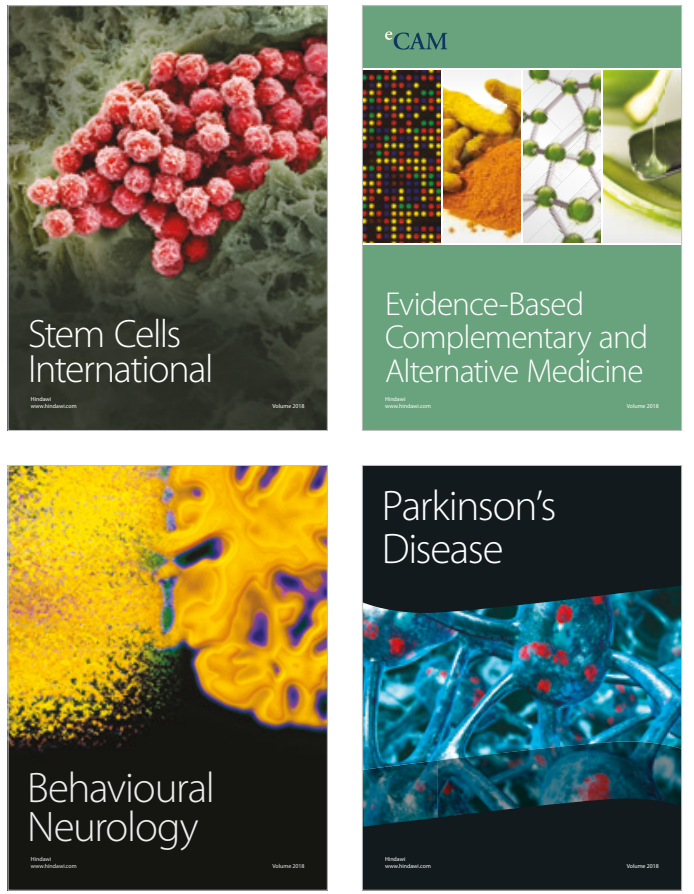

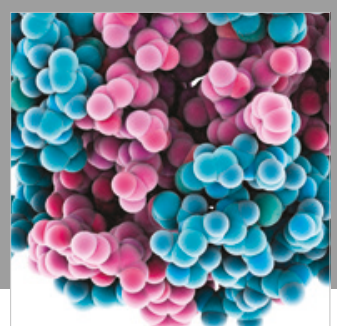

ournal of

Diabetes Research

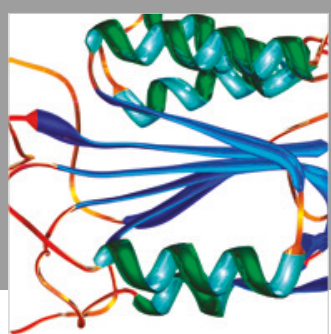

Disease Markers
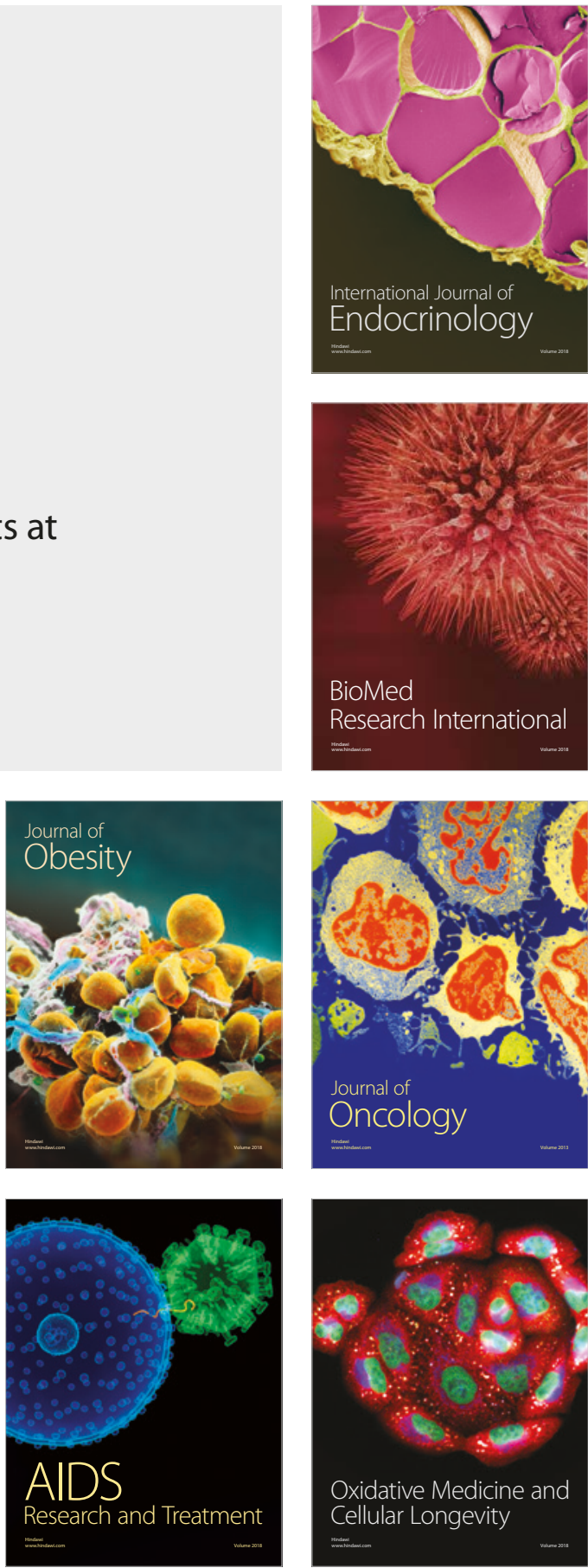